\title{
ARTIGO
}

\section{POR UMA EDUCACÃO OBSCENA A DESFOCAR NOSSOS CORPOS DE HIPO MULHERES}

\author{
Michele de Freitas Faria de Vasconcelos* \\ Universidade Federal de Sergipe (UFS), Itabaiana - SE, Brasil \\ Lívia de Rezende Cardoso** \\ Universidade Federal de Sergipe (UFS), Itabaiana - SE, Brasil \\ Jeane Felix ${ }^{* *}$ \\ Universidade Federal da Paraíba (UFPb), João Pessoa - PB, Brasil
}

RESUMO: Este texto se tece agenciado ao filme "Itão Kuêgü: as hiper mulheres". Com e a partir de imagens em movimento, criou-se um percurso que extrapolou a tela, sendo possível analisar pedagogias corporais denvolvidas na produção de cenários educacionais contemporâneos. Ensaiamos uma escrita que compõe imagens obscenas tomadas aqui como hiper mulheres, a desfocar nossos corpos de hipo mulheres: corpos generificados produzidos pelas decentes e boas pedagogias, corpos vestidos e educados por muitos ensinamentos, corpos em conformidade a um ser de determinado gênero. Objetivamos problematizar alguns modos em que aprendizagens de gênero ocorrem incessantemente nos currículos, mostrando-nos como homens e mulheres devem ser e se relacionar consigo e com os outros. Nesse movimento,operamos em favor da obscenidade da educação, no sentido do que é deixado fora de cena nos espaços educacionais, recompondo neles outros corpos em desaprendizagens, corpos hiper. Argumentamos, portanto, que é preciso desconstruir e desaprender os ensinamentos bipo para experimentarmos tantas outras subjetividades hiper mulheres. Currículos poderiam acolher a novidade obscena da vida?

Palavras-chave: Corpo. Relações de Gênero. Educação. Currículo.

\footnotetext{
"Doutora em Educação pela Universidade Federal do Rio Grande do Sul (UFRGS). Professora do PPGPSI e do Departamento de Educação (DEDI) da Universidade Federal de Sergipe, coordenadora do grupo de estudos e pesquisas Balbucios. Email: <michelevasconcelos@hotmail.com>.

" Doutora pelo Programa de Pós-Graduação em Educação, Conhecimento e Inclusão Social e pesquisadora do grupo de estudos e pesquisas em currículos e culturas (GECC) na Faculdade de Educação da UFMG. Professora do PPGED e do Departamento de Educação (DEDI) da Universidade Federal de Sergipe. Email: $<$ livinha.bio@gmail.com>.

"** Pós-doutora em Educação (UFRGS). Professora vinculada ao Departamento de Habilitações Pedagógicas, Centro de Educação/UFPB. Email: < Jeane Felix@gmail.com > .
} 


\section{FOR AN OBSCENE EDUCATION UNFOCUSING OUR HIPO WOMENBODIES}

ABSTRACT: This text is woven based on the movie "Itão Kuêgü: as hiper mulheres". With and from moving images, was created a course that extrapolated the screen, being possible to analyze corporal pedagogies involved in production of contemporary educational scenarios. We rehearse here a writing that composes obscene images taken here as hyper women, to blur our hipo women bodies: generalized bodies produced by decent and good pedagogies, bodies dressed and educated by many teachings, bodies conforming to a being of a certain gender. We aim to problematize some ways in which gender learning occurs incessantly in the curricula, showing us how men and women should be and relate to themselves and others. In this movement, we operate in favor of the obscenity of education, in the sense of what is left out of scene in educational spaces, recomposing in them other bodies in unlearning, hyper bodies. We argue, therefore, that it is necessary to deconstruct and unlearn hipo teachings in order to experience so many other hyper feminist subjectivities. Could curriculum accommodate the obscene novelty of life?

Keywords: Body. Gender. Education. Curriculum.

\section{Nota introdutória}

[...] era uma mulher sem nome. Ela não tinha nome porque não tinha. Mesmo que a chamassem de [algum nome]. Ter nome é ter um contorno de pessoa que possa caber, e ela não cabia. [...] vazava pelas bordas e pelo meio. Desde sempre [...] dançava. Nas tardes. Quando o vermelho do entre a noite e o dia invadia seu corpo ela se movia, indecente. Porque tudo que escorre é obsceno. E [ela] escorria. Como os seres sem nome das beiras líquidas sem contorno. Então [ela] se contornava naquilo que queriam que ela fosse. E foram tantas coisas estranhas à sua dispersa pessoa que nem mais lembrava. Quando acordada, quero dizer, quando em acordo com algum sentido, ela mesma acreditava na composição provisória que se havia proposto. E obstinava um contorno que independesse do seu dispêndio cotidiano. E que fosse fácil. Ela que brotou do meio. [Ela] havia germinado no entre das coisas. Naquele lugar limite entre o sentido e a ausência. Entre o nome e o fluxo. Pessoas são características que se pretendem fixas. E ela mar. E vento. E árvore. E casa. E armas. E letras impressas no papel. Acho que no fundo gostava de escapar de tudo que quisesse comprometê-la. Ela se achava solta no ar contra aquilo que a impedia e a libertava e a vida parecia ser mesmo assim. Sem forma própria, a não ser a que as coisas adquiriam quando em contato com a vontade de fazêl-las firmes e canônicas. Conceituais mesmo. Como pedras. Tijolos. Utensilios. Palavras, que no inicio palavras, mas depois prédios e configuracões que se erguiam na direção do que não poderiam jamais. Verter a vida em quadros. Como se neles coubesse. E nada mais. No entanto a força vibrante e alegre da vida pede passagem. Ei, ela disse. Existo aqui (MOSE, 2006, p. 48-49). 
Este texto endereça-se a colocar em suspensão aquela (nossa) vontade pedagógica de, em nome da "boa" educação, fazer as coisas firmes, canônicas, dicotômicas. Essa vontade de saber, essa pedagogia, ensinou e continua ensinando a ver o mundo e a estar no mundo de modo dividido e, ao mesmo tempo, hierarquizado. Uma mulher sem nome, sem contornos, que não cabe, que dança, que escorre, nos inspira a tomar o "obsceno" como conceito, como uma possibilidade de ir na contramão dessa vontade pedagógica. Gesta-se, assim, neste artigo, um desejo obsceno (porque tudo que se move, que escorre, que se movimenta é obsceno) de problematizar, desnaturalizar, desfazer o já feito, desmontar raciocínios tidos como 'normais'. Um desejo de desaprender todo um longo histórico de aprendizagens de gênero que operam em nossas culturas e, de forma subsequente, nos nossos currículos, inclusive os escolares, fazendo-nos crer por demais nos 'fatos', nas nossas características de mulher, materializando e naturalizando corpos de mulheres frágeis, recatadas, delicadas, faltosas, problemáticas quando não se portam como esperado.

Em um movimento de pensamento que se gesta em contrafluxo, somos afeitas a procurar por obscenidades, a tatear gestos, práticas, imagens e narrativas que tendem a ficar fora da cena dos cenários educacionais justamente porque têm a força de desnaturalizar esses 'fatos', desestabilizando a sina das práticas pedagógicas a veicular normas regulatórias por meio das quais se fazem nossos corpos, sempre generificados. Este texto nasce dessa busca e encontra uma estratégia para desfazer gênero no agenciamento com as artes visuais, mais particularmente o cinema.

Nessa direção, as análises aqui empreendidas se desdobram a partir do filme "Itão Kuêgü: as hiper mulheres" (2011), encenado por indígenas kuikuros e dirigido por Takumã Kuikuro (cineasta índio), Leonardo Sette (cineasta não índio) e Carlos Fausto (antropólogo). $\mathrm{O}$ filme foi produzido em um momento de facilidade de acesso às tecnologias digitais de imagem e som, o que trouxe a possibilidade das próprias comunidades indígenas construírem narrativas fílmicas, abarcando seus referenciais corporais, relacionais, espaciais e temporais. Essa possibilidade de narrar seu próprio cotidiano, estabelecendo diálogos intergeracionais, parece ter alavancado a motivação das lideranças Kuikuro na direção de produzir imagens em movimento, como o filme em questão, por meio do qual "seus autores e performers se fazem visíveis, para si e para os outros - os outros que não eles" (MARTINS, 2014, p. 752). Ainda de acordo com Martins (2014, p. 753): 
[...] o marco de partida é um exercício de negociação, em que a distinção entre os papéis de quem filma e é filmado é enfraquecida, na direção de se realizar um filme que, a despeito de transpirar um caráter etnográfico, observa uma estrutura narrativa com todos os elementos típicos de uma história ficcional, contada com imagens em movimento sonorizadas.

Nesse movimento de produção de imagens e sons, a figura do outro desfaz-se, perdendo a centralidade na narrativa fílmica. Essa foi a pista que perscrutamos: a narrativa fílmica que possibilitou ao povo kiukuro narrar performando sua própria história abriu espaço para a ideia de desenvolver, com este texto, uma político-ética de narratividade por meio da qual também pudéssemos perfomar nossas próprias histórias, numa espécie de instalação coletiva, produção de um comum filme-texto que se dá não pelo que nos aproxima, mas por excessos, pelo que faz vazar, borrando identidades fixas de gênero bem como a fixidez de culturas. O filme funcionou, assim, como uma espécie de trampolim para, por meio da escrita, tatear uma habitação das fronteiras de nossos mapas políticos, linguísticos, culturais, educacionais. Compomos, então, os movimentos analíticos que dão forma a esse artigo tomando emprestada a força do cinema (ou pelo menos certos modos de fazer cinema) de tocar/encantar/ampliar a vida, fabular uma vida (VASCONCELOS; BALESTRIN; PAULON, 2013).

Patrícia Balestrin e Rosâgela Soares (2012, p. 91) afirmam a potência de analisar as "imagens em movimento, indicando para a importância de atentarmos tanto para os 'elementos que estão em tela' quanto para aqueles outros que 'não aparecem de imediato'. Para as autoras, na análise fílmica, devemos estar atentos(as) para "criar com e a partir das imagens em movimento; criar quem sabe novos movimentos que possam extrapolar a tela. Um movimento de pensamento, um pensar em movimento" (BALESTRIN; SOARES, 2012, p. 91).

Em outros termos, o filme "Itão Kuêgü: as hiper mulheres" (2011) foi entendido como um artefato cultural por meio do qual é possível pensar, por um lado, na 'estranha' e obscena feitura dos corpos das 'hiper' mulheres kuikuro que se apresentam ao longo das cenas e, por outro, na recatada e repetida montagem de 'nossos' corpos de 'hipo' mulheres. Em outros termos, operamos um movimento analítico a partir dos conceitos de corpo e gênero, que intercala passagens do filme com situações já vivenciadas e/ou analisadas em nossas atuações como professoras ou pesquisadoras em cenários educacionais.

Corpo e gênero são aqui tomados como construções sociais e históricas, não fixas, não lineares (MEYER, 2008) e apesar de tradicionalmente serem coladas em corpos masculinos ou femininos, considerar que o conceito de gênero se fia nos corpos 
de homens e mulheres é esvaziar a potência de seu uso. Nossos corpos são generificados, mas nossas instituições são generificadas, nossas práticas educativas são generificadas. Gênero é pessoal, social, político, histórico (LOURO, 2004). Corpos são pessoais, sociais, políticos, históricos, éticos. Gênero e corpo se articulam na medida em que, em nossas culturas, as "normas de gênero ainda são imprescindíveis na montagem dos corpos humanos e de suas identidades" (VASCONCELOS \& SEFFNER, 2015, p. 264). Assim, constituem-se pedagogias corporais de gênero que fazem corpos de homens ou mulheres, masculinos ou femininos, determinadas formas de ser e estar no mundo e isso limita, amarra, congela, despotencializa a invenção de outros modos de vida.

Na contramão dessa fixidez naturalizada, parece ser importante deixar evidente que os modos de fazer corpos, fazer cinema e fazer ciência dão-se em determinadas circunstâncias culturais, políticas, subjetivas convencionais, convencionadas. Assim, trazemos algumas cenas do filme que excedem da (nossa) aparente legitimidade e conformação sociocultural, para produzir imagens e narrativas obscenas sobre nós mesmas, para nos estranharmos, 'outrarmo-nos', num exercício de desnaturalização e problematização de cenários educacionais generificados observados em nossas inserções como pesquisadoras e formadoras de profissionais da educação, buscando suscitar reflexões em torno de corpos, gêneros, subjetividades. Apostamos, pois, na possibilidade de pensar na produção dos corpos de mulheres a partir e para além do filme analisado. Argumentamos que as hiper mulheres são uma possibilidade de existência que permite movimentarmos o pensamento e mexermos com a fixidez de pedagogias de corpo e de gênero, como desenvolveremos a seguir.

\section{ITÃO KUÊGÜ: DAS (IM)POSSIBILIDADES DE DESFAZER NOSSOS CORPOS DE HIPO MULHERES}

Ela tem que cantar uma última vez, pede, na primeira cena do filme,um ancião da aldeia para que se realize o maior ritual feminino de cantos sagrados do Alto Xingu, no estado de Mato Grosso, pois sabe que a morte, tão natural ${ }^{1}$, aproxima-se da sua companheira. $O$ pinto dele já está murcho/ o Sol murchou o pinto, cantam e riem mulheres kuikuro a caminho do rio ao encontrarem um senhor muito bemhumorado e um dos mais carismáticos personagens. Vem, eu quero você, você não pode me rejeitar, divertem-se as hiper mulheres, em noite de festa, "atacando" homens em suas redes para representarem uma 
lenda sobre suas origens. Mulher chefe, venha lutar, chamamento às mulheres que lutam e que ganham peixes, beijus e redes como oferta dos anfitriões. Eu sou uma hiper mulher, eu sou uma hiper mulher, en sou Ijalu, cantam as crianças, as jovens e as anciãs em coro, marcando os passos de uma dança em tarde de Jamurikumalu ao final do filme.

Entre cantos, ritmos, risadas, tradições e alegrias, fomos tomadas pelas subversões que esses personagens nos apresentam no filme. Suas cenas misturam realidade e ficção para contar - fazendonos entrar subitamente no cotidiano dessa cultura - a história das mulheres kuikuro: as hiper mulheres.

\footnotetext{
As mulheres são protagonistas, porque hiper mulheres, como o título antecipa. Kuegü, da língua falada pelo povo kuikuro, foi traduzido como hiper, ocupando o lugar de superlativo, e itão corresponde a mulheres. Como o filme conta a preparação e a realização do Jamurikumalu, ritual feminino do Alto Xingu, no Mato Grosso, o título realça a centralidade das mulheres no ritual e no filme, e sua força que se estende desde a situação extraordinária da festa ao cotidiano da comunidade (MARTINS, 2014, p. 753).
}

Neste artigo, tomadas pela potência que elas nos incitam a experimentar, utilizamos esse conceito de hiper mulheres como uma possibilidade de movimentarmos o pensamento e mexermos com os conceitos de corpo e de gênero que são operados nos cenários educacionais que temos presenciado em nossas inserções como pesquisadoras e formadoras de profissionais da educação.

O título e o argumento central deste artigo foram inspirados num agenciamento entre a poesia de Viviane Mosé (2006), que abre este texto, e uma passagem do artigo de Alice Fátima Martins, chamado "As hiper mulheres kuikuro: apontamentos sobre cinema, corpo e performance" (2014), no qual a autora diz que, para a divulgação do filme, abriu-se uma página no site de relacionamento social Facebook. Nesta página, dentre outras curiosidades e dados, foram inseridas imagens dos cartazes, fotos de ambientes de filmagem etc.

Alice segue apontando que a administração da página de relacionamento social censurou as fotos nas quais as mulheres aparecem desnudas de frente, exibindo o corpo inteiro. A justificativa para a censura se apoiou no princípio do bloqueio à pornografia, ou exposição de nus, que pudessem ofender a moral dos e das demais usuários/as ligados/as àquela rede de relacionamentos. "Determinou-se, então, que se colocassem tarjas pretas nas imagens, ocultando os seios e o púbis das mulheres" (MARTINS, 2014, p. 761). A autora ainda questiona:

Por que os corpos dessas mulheres são censurados, de modo não negociável, enquanto imagens de quantos outros corpos femininos, masculinos e de outros gêneros, nus ou seminus, com apelo erótico ou não, têm assegurado espaço de 
mercado e de publicação nessa mesma rede? De que informações são portadores tais que justifique sua adjetivação como obscenos? $\mathrm{O}$ verbete obsceno, de origem latina, refere-se ao que é vulgar, indecente, sem pudor, e, por isso mesmo, ofensivo. Mas obsceno também tem o sentido daquilo que está fora da cena, que não comparece ao campo visível, e por isso mesmo provoca a imaginação. Nas artes da cena, o que não é mostrado, mas sugerido, ganha potência. A expressão fora da cena também qualifica aquilo que não deve ser trazido à presença da audiência, que deve ser ocultado - eventualmente até mesmo apagado - não só do campo da visão, como também da memória (MARTINS, 2014, p. 761-62).

Inspirando-se em Baudrillard, Alice Martins (2006, p. 762) segue afirmando que, "numa história que pudesse ser produzida sobre o corpo, o percurso iria desde o sexo escondido à emergência da nudez. [...] E, quando o corpo nu emerge, é como corpo de mulher", obsceno. "Mergulhado nas políticas de controle sobre o corpo, o obsceno mantém-se como interdito" (GERACE, 2015, p. 10) porque tem a força de romper com a norma. Mas o que deve ser mesmo ocultado do campo da visão e da memória que (trans)parece nos corpos das hiper mulheres? O que seus corpos fazem vazar, exceder? Que convenções tais corpos fazem exibir como ficções (produções culturais)?

Em nossas culturas (capitalistas) ocidentais, em nosso tempo histórico, as palavras gêneroe educação parecem terassumidocontornos de prescrição, normalização, formas de ação, homogeneização, restringindo e apequenando a vida, barrando trânsitos, fazendonos hipo. O que estamos querendo afirmar é a ideia de que nossos corpos (generificados) são educados por meio de um conjunto de processos que nos conformam, e pelos quais somos conformadas e conformados, em mulheres e homens, de determinados modos (barrando - patologizando/anormalizando - tantos outros modos possíveis, inclusive os ainda porvir, barrando movimentos e trânsitos).

No povo kuikuro, como que transgredindo uma moral de faixa etária e de gênero 'feminino', corpos de mulheres e corpos de meninas se misturam, envolvem-se, movimentam-se em processos contínuos de aprendizagem. Em muitas cenas, no chão, ao lado de uma rede, na fila e nos passos marcados da dança, no canto repetido ou gravado em fita e na memória, nos banhos de rio, nas lutas, na sedução aos homens em noite de festa, esses corpos de hiper mulheres apresentam possibilidades de desaprendizagens sobre o que conhecemos, sobre o que nos compõe como bipo mulheres.

As hiper mulheres kuikuros exibem e expressam corpos que "colocam à mostra as inscrições de suas histórias pessoais e de grupo" (MARTINS, 2006, p. 762). A despeito de uma moral da vida ativa e da corrida nossa de todo dia rumo ao corpo perfeito das "barbies", esses são corpos que se dão a ver: 
[...] sem dissimular a textura da pele, dos cabelos, a forma dos quadris, das pernas. São porosos, irregulares, não se deixam plastificar - tanto no sentido de se cobrir por alguma película impermeável, quanto de se submeter a cirurgias plásticas. Embora estejam cuidadosamente vestidos, adornados e com a pele coberta por desenhos, obscenamente não foram encerados ou vitrificados, tampouco se pretendem perfeitos e aspiram à imortalidade. Ao contrário: a proximidade da morte de uma dessas mulheres é que as move para a festa, para o ritual. Ocupam a cena, dando-se a ver (MARTINS, 2006, p. 762-63).

Com as kuikuro, ocorre-nos pensar que a noção de corpo perfeito (e, portanto, inalcançável?) vendida pelas diversas mídias, pelos distintos currículos culturais e pelos serviços de medicina estética, não é algo que pareça fazer sentido no contexto das mulheres às quais nos referimos aqui. Dando pistas sobre a perfeição e dialogando com um investimento cultural para plastificar também o sentido do termo beleza, gostaríamos de chamar a atenção para a multiplicação também desse termo.

Corpos de hiper mulheres, corpos em performances que nos convidam a desdizer e a transver, desfocar todo um longo histórico de aprendizagens de gênero a barrar a dança de um vir-a-ser mulheres, todas, cada uma, qualquer, nenhuma... "Afinal, que pessoas e quais comunidades [, que mulheres] permanecem as mesmas no decurso do tempo?" (MARTINS, 2006, p. 764).

Apostamos, pois, na potência da desnaturalização dos currículos culturais que vão constituindo pedagogias de gênero e de corpo, na medida em que estão "envolvidos numa economia do afeto que busca produzir certo tipo de subjetividade e identidade social" (SILVA, 2002, p. 136). Os currículos culturais destacam a importância de atentarmos e colocarmos sob suspeita aqueles currículos produzidos dentro e fora dos espaços escolares e que com muita força e intensidade "contribuem para a formação das pessoas e que disputam espaço na produção de sentidos e dos sujeitos" (PARAÍSO, 2007 , p. 24), no caso de nossas culturas ocidentais capitalistas, sujeitos sexuados, generificados e sexualizados.

Neste artigo, por entendermos que as aprendizagens de gênero se dão a todo o momento nos currículos de diferentes cenários educacionais - em conteúdos, atividades, incentivos, chamamentos, brincadeiras ou materiais pedagógicos -, mostrando-nos como homens e mulheres devem ser e se relacionar consigo e com os outros, operamos em favor da obscenidade, do que é deixado fora de cena nos espaços educacionais, o 'fora', o interstício, a movência, a obscenidade dos corpos, a qual poderia transformar, talvez, corpos hipo em hiper. Argumentamos, portanto, que é preciso problematizar, desconstruir, 
desaprender os ensinamentos hipo para produzirmos tantas outras subjetividades hiper mulheres, devir-mulheres, abrindo nossos corpos para a mu-dança da vida, pois vida é mar, inunda, rebenta represas.

O convite é para pensarmos sobre como relações de gênero nos compõem, atravessam nossos corpos, e, na maioria das vezes, em nossas feituras de gênero, barramos trânsitos e nos entrincheiramos, pois, para nos tornarmos corpos inteligíveis, de mulheres ou de homens, habitar fronteiras não nos é possível. Recatados contornos a colocar entre parênteses a incontornável obscenidade de uma vida que sempre vaza, não cabendo em quadros.

\section{CORPOS (S) EM CENA}

Nestes tempos atuais, em que se tem ouvido muito falar em 'ideologia de gênero', é comum tal expressão vir acompanhada de um veto, de um "não" a práticas de problematização sobre o que entendemos como formas "normais" de experimentar/performar corpo, gênero e sexualidade nas escolas e fora delas. No debate sobre essa tal ideologia de gênero, as pessoas têm tomado partido situando-se em duas extremidades: 1) que não se fale sobre gênero e sexualidade nas escolas; 2) que é preciso falar sobre gênero e sexualidade nas escolas. $\mathrm{Na}$ tentativa de ultrapassar esse 'sim ou não' que muitas vezes polariza e paralisa a nossa capacidade de análise e intervenção, uma das questões que propomos que pensemos juntas/os é: Como temos falado sobre relações de gênero e sexualidade nas escolas? Que projeto de educação temos desenvolvido e, com ele, que relações de gênero queremos viver?

Parece-nos que (nossa) vontade pedagógica de, em nome da "boa" educação, fazer as coisas firmes, canônicas, dicotômicas, ou isso ou aquilo e nada mais, é uma vontade desde sempre generificada. As próprias instituições educativas (assim como as demais instituições sociais) são todas elas também generificadas. Essa vontade de saber e de poder barrar o movimento da vida e dos corpos, essa pedagogia ensinou e continua ensinando a ver o mundo e a estar no mundo de modo dividido e ao mesmo tempo hierarquizado, a estar no mundo ou como homens ou como mulheres de um determinado e único jeito. Ou seja, gênero já faz parte de nossos currículos, pedagogias de gênero e sexualidade; mesmo que na maioria das vezes de forma "oculta", operam nos conteúdos, nos espaços, nas atividades, na vida escolar.

Antes de prosseguirmos, um adendo: entendemos gênero como uma norma, uma prática regulatória por meio da qual se produz e se governa corpos de homens e mulheres. Sendo assim, ele 
não se reduz a papéis e funções de homens e mulheres, mas atravessa a constituição e o funcionamento de instituições, símbolos, normas, leis, serviços assistenciais, políticas sociais, corporais, modos de viver e conviver em uma dada sociedade, práticas educacionais, pedagogias (MEYER, 2003; VASCONCELOS \& SEFFNER, 2015).

Tal norma é comumente entendida como heteronorma, é uma "prática reguladora" que produz efeitos na "relação entre sexo, gênero, prática sexual e desejo", o que engendra gêneros (BUTLER, 2010, p. 39). Pode ser entendida, ainda, como "regime da heterossexualidade [que] atua para circunscrever e contornar a 'materialidade' do sexo e essa 'materialidade' é formada e sustentada através de - e como - uma materialização de normas regulatórias que são, em parte, aquelas da hegemonia sexual" (BUTLER, 2007, p. 170). Ao analisar o dispositivo da sexualidade, mais especificamente em sua construção do século XX, Foucault afirma que essa norma consistiu em "reduziro sexo à sua função reprodutiva, à sua função heterossexual e adulta e à sua legitimidade matrimonial" (FOUCAULT, 2010, p. 114). Aos (des)sabores desse conjunto de normas, quer-se uma identidade para um corpo e uma outra para outro corpo. Assim, em um sistema heteronormativo, caberiam, apenas, duas identidades de sexo/gênero/desejo: pênis ou vagina, mulher ou homem, masculino ou feminino e todos heterossexuais.

Tal hipótese binária encerra "a crença numa relação mimética entre gênero e sexo, no qual o gênero reflete o sexo ou é por ele restrito" (BUTLER, 2010, p. 24). Esses gêneros, no entanto, não diferem apenas pelo seu sexo, mas "por toda uma constituição física e moral” (CORBIN, 2008, p.185). Porém, aqui, preferimos entender que gêneros e sexualidades apontam "não para uma essência feminina ou masculina (natural, única ou mutável), mas para processos determinados e múltiplos de construção discursiva" (PARAÍSO \& GONÇALVES, 2009, p. 03), históricos e cambiantes. Isto é, "gênero não pretende significar o mesmo que sexo" (LOURO, 1995, p. 09). Para Butler (2010), o sexo, o corpo sexuado é produzido cultural e discursivamente. Para ela, não há um sexo biológico e um gênero, que seria a construção social desse sexo biológico. O próprio sexo é também uma construção cultural. Desse modo, as características generificadas destinadas aos corpos não nasceram neles, mas situadas num jogo de verdades e poderes, tais características (naturalizadas) - por meio das quais eles se organizam, ganham contornos precisos - os hierarquizam, os fazem valer mais ou menos.

Todavia, corpos sempre podem mais do que valem! Além de construto político-cultural, corpos são construções político-éticas. Ou seja, mais do que afeitos à submissão a determinadas pedagogias 
culturais e à toxicomania identitária que lhes marcam, ensinam-lhes 'boas' condutas, avaliam seu valor, os corpos tendem ao singular, ou melhor, à singularização. Situando-se em fendas do jogo do poder, corpos abandonam a adesão obediente às fôrmas subjetivas prescritas por tais pedagogias (entre tantas outras, as de gênero), recusam o que são e ensaiam a invenção de outros modos de existir, outras formas de subjetividade, abrindo-se para outras práticas de si que não as bioidentitárias, pautadas pela sujeição a um 'eu' que, nos dias atuais, se expressa num 'corpo', perfeito, plastificado e generificado, que se precisa mostrar, conformando "subjetividades exteriorizadas", como diria Ortega (2008).

Gesta-se, pois, o desejo obsceno (porque tudo que se move, que escorre é obsceno) de se desmontar raciocínios generificados, performar currículos e práticas pedagógicas desgarrados do desejo de seguir materializando e naturalizando (nossos) corpos de hipo mulheres. Ir na contramão dessa (nossa) vontade pedagógica que normaliza os corpos de mulheres, tornando-as como frágeis, recatadas, delicadas, faltosas (falta-lhes força, falta-lhes pênis), problemáticas quando não se portam como esperado.

Esse ensino-aprendizagem autoriza frases do tipo: "Menino, pare de chorar agora, é mulherzinha, é?" (REIS, 2011); "Menina, feche as pernas!" (CARVALHAR, 2010). Esse ensino-aprendizagem inscreve-se em atividades corporais tidas como de meninos e meninas, como, por exemplo, futebol é para meninos, dança para meninas. Esse ensino-aprendizagem naturaliza a agitação e a dificuldade de concentração entre meninos e coloca como problemáticas, adoecendo toda e qualquer menina que se apresente como inquieta, agitada, com dificuldade, por exemplo, de leitura (CALDEIRA; PARAÍSO, 2016). Outro exemplo interessante da generificação dos ambientes educacionais, ou seja, de pedagogias de gênero operando nas escolas e fazendo corpos de homens e de mulheres a partir de normas regulatórias, é observado numa pesquisa realizada no Reino Unido (LAVY; SAND, 2015), indicando que professoras/es dão notas inferiores em matemática para as alunas, quando sabem que estão corrigindo a prova de uma menina.

Em outra investigação, pesquisadoras observam aulas de matemática sendo construídas de modo a se direcionarem para os meninos, quando professoras chamam insistentemente alunos para irem ao quadro mostrar que sabem resolver problemas matemáticos e permitem zombarias sobre as meninas (SANTOS \& FELIX, 2014). Há, ainda, situações de aprendizagens de gênero que acontecem em aulas de ciências, quando há o investimento em solicitar que meninas manuseiem os experimentos - por serem "delicadas", "organizadas" 
e "atenciosas" - e que meninos argumentem acerca dos dados produzidos em tais atividades - por serem "inteligentes", "lógicos" e "racionais" (CARDOSO \& PARAÍSO, 2015). Em ambas as situações, não se estabelece uma equidade de gênero na produção e apropriação desses saberes escolares.

Não é apenas na escola, porém, que fôrmas de gênero são construídas. O processo educativo se desenvolve em outros espaços, em outros currículos, em outras pedagogias (PARAÍSO, 2004). Produções cinematográficas que circulam dentro e fora da escola, voltadas ao público infantojuvenil, por exemplo, vêm sendo amplamente analisadas em pesquisas que investigaram, entre tantos aspectos: os romances amorosos em filmes da Disney (SABAT, 2002), a natureza como produtora de generificações (KINDEL, 2003), a superioridade dos homens (necessariamente masculinos) em ficções científicas (CRUZ, 2007), a beleza e a bondade femininas (necessariamente características de mulheres) (SILVA e MAIA, 2014) e o papel secundário da mulher em filmes de animação com temáticas científico-tecnológicas CARDOSO, 2016).

Em outros artefatos culturais, que são igualmente cenários educacionais, também é possível vislumbrar pedagogias de gênero ensinando e compondo masculinidades e feminilidades: nas histórias em quadrinhos (FREITAS, 2008), nos livros didáticos (CARDOSO, 2014), em sites de relacionamento (SALES, 2010), em sites de relacionamento gay (VASCONCELOS \& ZAGO, 2015). E essa lista poderia ir longe... Em que se sustenta essa "evidência" que se faz natural das condutas educacionais e dos corpos de meninos e meninas nas escolas e fora delas?

Em nossas culturas ocidentais contemporâneas, mulheres têm seus corpos, suas subjetividades sequestradas por práticas educativas que falam em seu nome ${ }^{2}$. As palavras gênero e educação parecem ter assumido contornos de prescrição, normalização, fôrmas de ação, homogeneização, restringindo e apequenando a vida de toda e qualquer mulher. Nesse sentido, práticas e discursos educacionais evidenciam um determinado modo de pensar e agir sobre os corpos, que se conectam a ações históricas e socialmente construídas, mas que passam a ser tidos como corpos "naturais" e, por isso, generalizáveis, "universais", sobrecodificando a história singular de cada grupo de mulheres e de cada mulher. O que estamos querendo afirmar é a ideia do corpo como construção sociocultural:

[...] a cultura não é universal, nem está dada de antemão, é ativamente produzida e modificada, ou seja, poderíamos pensá-la como o conjunto dos processos pelos quais 
se produz um certo consenso acerca do mundo em que se vive. Nessa direção, corpo adquire determinados sentidos no contexto da cultura [...] em que é compreendido e experienciado (MEYER, MELLO, VALADÃO; AYRES, 2006, p. 1337-38).

Com Dagmar Meyer, entendemos por cultura um campo de disputa de práticas e sentidos passíveis de serem compartilhados por um dado grupo. Assim, “o que é pode ser diferente" (VEYNE, 2008, p. 240), pois podemos pensar contra o nosso tempo e transformar as culturas nas quais estamos inseridos/as, borrar noções de referenciais identitários fixos masculino ou feminino, homem ou mulher, abrir espaço e adensar discussões, análises, intervenções coletivas e cotidianas no sentido de produzir modos de barrar práticas desrespeitosas e preconceituosas aos corpos e aos saberes das mulheres, de colocar em cena outras aprendizagens de gênero. Nossa aposta é pela invenção de múltiplas e diferentes possibilidades de ser homem e ser mulher na nossa cultura e essa invenção, de muitas formas, vem sendo produzida por diferentes sujeitos e grupos e culturas, a exemplo das hiper mulheres que vimos trazendo para ilustrar este texto.

Para além da binária discussão se gênero deve ou não estar presente como uma disciplina escolar, como conteúdo ou como adendo em materiais pedagógicos, é preciso reconhecer que falamos e produzimos corpos generificados a todo o momento. Falamos de gênero até mesmo no mais profundo silenciamento que emitimos frente a uma violência, um xingamento ou uma piadinha entre colegas. Produzimos modos de relacionarmos com os nossos corpos até mesmo nas mais antigas formas de vestirmos, fantasiarmos ou dispormos meninas e meninos em nossos cotidianos. Assim, não é qualquer corpo que entra nas cenas educacionais. Vemos, reiteradamente, corpos serem retirados ou encenados como personagens de menor valor, como bipo.

\section{DESNUDANDO CORPOS, DESFAZENDO GÊNEROS}

Obsceno: alguma coisa que não deve ser exposta. Qual o sentido dessa interdição, desse esconderijo? Para Rodrigo Gerace (2015), amparado em Susan Sontag, a obscenidade é uma convenção sociocultural, ficção imposta à natureza por sociedades convictas de que haveria algo vil nas funções e no prazer sexual. Com esse mesmo autor, entendemos a importância de perguntar sobre que função política pode ter a obscenidade.

A performance 'obscena' de corpos nus de mulheres kuikuros parece ser um modo de desfocar os nossos olhos de espectadores/as, expondo a sua pequenez: “o 'efeito obsceno' só tem sentido quando 
colocado em cena - on screen - [...] já que o obsceno é aquilo que está fora de cena por ferir o pudor e que deve ser escondido. Assim, quando levado à cena, torna-se obscena" (GERACE, 20015, p. 3132), expondo-se como revelação ou transgressão. Ao nos agenciarmos com a exibição de corpos hiper, o objetivo foi expor as normas excessivamente moralizadas de feitura de (nossos) corpos hipo, numa tentativa de redimensionar os limites do obsceno e apresentar novas formas de nos exibir, pela desconstrução de critérios culturais e políticos que norteaim os conceitos de corpo e gênero.

A essa altura do texto, esperamos ter ficado evidente que objetivamos pensar obscenamente a educação, ou seja, pensar contra o nosso tempo, abrir fissuras, ampliar focos de visão. Para isso, gostaríamos de fazer quatro apontamentos que podem ajudar a desencaminhar, desnaturalizar, desfocar um modo dado de fazerpensar gênero, performando outros tantos modos. A ideia é indicar norteadores teórico-metodológicos que possam dar pistas para outras professoras e pesquisadoras a tatear uma educação antinormalizadora, pós-identitária.

1) O primeiro é a pista medológica sobre a raridade dos fatos humanos, que Paul Veyne (2008, p. 240) anuncia em "Foucault revoluciona a história": "os fatos humanos são arbitrários, não são óbvios, no entanto parecem evidentes aos olhos dos contemporâneos que nem sequer o percebem". Acreditamos em "evidências", ou seja, numa essência ou natureza das coisas, num "algo que é como é", "que é porque sempre foi" na mulher, no homem, na educação, que os homens são assim (do modo como são e se portam) e as mulheres assado (do modo como são e se portam). Mas, a despeito dessa nossa crença, não há coisas nem objetos naturais. As coisas, os objetos, os sujeitos não têm existência em si e por si, não são senão correlatos de práticas sociais muito bem datadas, ou seja, são produções histórico-culturais.

2) O segundo versa sobre a ideia de que, no interior de uma cultura, em um dado momento histórico, conformam-se formas possíveis e inteligíveis de ser homem e de ser mulher. Não somos mulheres e homens, nos fazemos mulheres e homens pelo engajamento reiterado a normas regulatórias de gênero veiculadas e inscritas nos corpos. Desse modo, a 'simples' e tão conhecida expressão 'É um menino' ou 'É uma menina' não dá nome a uma realidade dada de antemão, mas o próprio ato de nomear instaura todo um processo de fazer desse corpo um corpo de homem ou de mulher. "Um processo que é baseado em características físicas que são vistas como diferenças e às quais se atribui significados culturais" (LOURO, 2004, p. 15-16). Tal nomeação é "prescritiva, e não descritiva", isto é, produz "uma 
invocação performativa [com] efeitos protéticos: faz corpos" (BENTO, 2006, p. 88). Tal nomeação opera no sentido de fixar uma "sequência sexo-gênero-sexualidade" (LOURO, 2004, p. 15) vista como 'natural' e, portanto, correta e única. As normas de gênero produzem, assim, corpos e sujeitos sexuados, generificados, sexualizados, normalizados. Os "corpos que importam", os "sujeitos legítimos" (LOURO, 2004, p. 15) são aqueles que obedecem a essas normas regulatórias. Ou seja, corpos se generificam no interior de uma cultura que:

[...] não é universal, nem está dada de antemão, mas é ativamente produzida e modificada, ou seja, poderíamos pensá-la como o conjunto dos processos pelos quais se produz um certo consenso acerca do mundo em que se vive. Nessa direção, corpo adquire determinados sentidos no contexto da cultura [...] em que é compreendido e experienciado (MEYERet al., 2006, p. 1337-38).

3) O terceiro apontamento se refere ao fato de que nossos corpos se gestam e se organizam por meio de marcas políticoculturais. A intercessão entre gênero e outros marcadores sociais como raça/cor e etnia, geração, região, classe social, escolaridade, vai marcando diferentes formas de ser/estar mulher e homem nesse mundo. Cada uma dessas articulações entre gênero e marcadores socioculturais produz modificações importantes nas "formas pelas quais as feminilidades ou as masculinidades são, ou podem ser, vividas e experimentadas" (MEYER, 2008, p. 17). Desse modo, afirma-se a existência de muitas e conflitantes formas de definir, viver, ser/estar homem ou mulher numa dada cultura. Seja como for, na articulação entre gênero e cada um desses marcadores sociais, há formas de ação prescritas em relação a como ser homem ou mulher.

4) O quarto considera que, assim como a cultura é um campo de disputa de práticas e sentidos passíveis de serem compartilhados por um dado grupo, o corpo é "espaços de luta e de experimentação, espaço conflitivo de submissão e de subversão" (PARAÍSO, 2011, p. 149). Nessa direção, Judith Butler afirma que a materialização dos corpos feitos por meio de normas de gênero "nunca é totalmente completa, que os corpos não se conformam nunca completamente às normas pelas quais sua materialidade é imposta" (2007, p. 154). Os corpos são, assim, entendidos como construções histórico-culturais, mas também éticas, "espaços de experimentação". Corpos se tecem encarnando normas regulatórias de gênero, mas também (re)existem, (trans)formam-se, desfazem toda uma linearidade e fixidez de gênero dada de antemão.

\section{MOVIMENTAR O QUE PARECE ÓBVIO: POR OBSCENIDADES NA EDUCAÇÃO}

Se "o que é pode ser diferente" (VEYNE, 2008, p. 240), podemos pensar contra o nosso tempo e transformar as culturas nas 
quais estamos inseridos/as, abrir espaço e adensar discussões, análises, intervenções coletivas e cotidianas no sentido de produzir modos de barrar práticas desrespeitosas e preconceituosas ao corpo e aos saberes das mulheres. Assim, corpos experimentam uma contramarcha, uma contramemória, uma desaprendizagem. Dessa forma, gesta-se, por exemplo, em nossos tempos, a "marcha das vadias", para expressar, contrariando ensinamentos machistas que conformam corpos de homens e mulheres, que podemos fazer de nossos corpos de mulheres o que quisermos, sem seguirmos culpabilizadas por violências e violações, lembrando, dentre uma série de violências e violações, que a cada quinze segundos uma mulher é agredida no Brasil.

Nesse aspecto, como os corpos das hiper mulheres que precisam cantar e dançar, nossos corpos, em seus cotidianos, performam, fazemse corpos de mulheres e, nessa feitura, gradualmente transformam-se, ganhando força e exuberância na medida em que ousam despir-se de normas regulatórias de gênero, abrindo-se para o imponderável da experiência, ápice da festa na plenitude de sua transfiguração: abrir o corpo para desaprendizagens de gênero. Nesse sentido, "nas condições extraordinárias da experiência” (MARTINS, 2006, p. 657), talvez possamos cantar e dançar no vermelho da tarde, nos despir do adjetivo hipo, talvez possamos transitar entre fragilidade e força, compartilhando e tramando sentidos para as mulheres que seguimos sendo: corpo-tensão entre, de um lado, as formas que pedem pela conservação de modos prescritos de ser mulher que naturalizam desigualdades hierarquizadas entre mulheres e homens e entre grupos de mulheres; de outro lado, as forças que impulsionam os corpos para mudanças, o vir-a-ser...

Afinal, o que seria um corpo, senão uma instância de infinitas possibilidades e potencialidades? "Meu corpo é como a Cidade do Sol, ele não tem lugar, mas é dele que saem e irradiam todos os lugares possíveis, reais ou utópicos" (FOUCAULT, 2013, p. 14). O convite é para considerar as singularidades de cada mulher, bem como suas singularizações, seus momentos de vida, seus trânsitos, pois somente o tempo, suas andanças e a tessitura de suas histórias vão lhes revelar quem são. E, nós, temos vontade de cantar e dançar.

A partir dos apontamentos supracitados, quem sabe ousemos ensaiar uma educação obscena de modo a interferir na paisagem humana instituída como única, legítima, caminho reto e universal, mostrando que "há muitas possibilidades de se fazer gênero" (BENTO, 2006, p. 16). Se o que tem sido tem trazido sofrimento e restrições existenciais e sociais, podemos pensar contra o nosso tempo e transformar as culturas nas quais estamos inseridos/as, 
podemos borrar noções de referenciais identitários fixos masculino ou feminino, homem ou mulher, abrir espaço e adensar discussões, análises, intervenções coletivas e cotidianas no sentido de produzir modos de barrar práticas desrespeitosas, preconceituosas, violentas.

Talvez, tateando um descaminho, possamos interferir em cenas corriqueiras, generificadas e naturalizadas, de modo a injetar vida em vez de insuflar violências (mesmo com o simples gesto de fingir não ver sob a alegação de que não se foi capacitado/a para lidar com tais questões). O que fazemos quando, por exemplo, um menino tido como feminino é chamado de "veadinho"? Quando uma mulher transexual quer usar o banheiro e é violentada por meninos e meninas ou desenvolve uma infecção urinária de tanto segurar a urina ou tem sua cabeça posta na água da latrina por ousar ferir normas de gênero? O que fazemos quando um menino é ridicularizado por preferir andar com meninas? Quando uma menina não consegue estudar melhor por ter de, sozinha, ajudar a mãe nas tarefas de casa, tendo mais cinco irmãos que poderiam ajudar, mas, ops, são homens? O que fazemos viver por meio de nossas práticas formativas? Preconceitos, violências ou ampliação de vida e modos de conviver? Formatamos (conformamos formas conformadas) ou transformamos (deixamos germinar a intensidade das forças brincantes)?

O convite foi e é o de abrir o corpo da nossa educação para desaprendizagens de gênero. Assim, nas condições extraordinárias e singulares de cada corpo, de cada experiência, de cada aprendizagem, de cada encontro, talvez possamos tramar novos possíveis para nossas práticas formativas: tensão entre, de um lado, a sina da fôrma-de-ação, que pede pela conservação de modos prescritos de ser mulher ou homem, naturalizando desigualdades hierarquizadas entre mulheres e homens e entre grupos de mulheres e homens; de outro lado, a força de uma conspiração por outras formas-de-ação que possam impulsionar os corpos para mu-danças, um vir-a-ser...

O povo kuikuro nos incitou tatear, ao menos pela escrita, uma política, um outrar, uma narrativa que possa ousar desdizer todo um longo histórico de aprendizagens de gênero, que fazem de tantos corpos, corpos de hipo mulheres. Como professoras, como mulheres, como a vida sem nome, sem lugar, sem gênero que em nós pede passagem, tateando formas de vida hiper, nossa vontade segue sendo a de ensaiar passos em mu-dança, acompanhar a força de (nossas) vidas que brotam no meio, que germinam no entre das coisas. Desejo de experimentar modos de educar antinormalizadores, uma educação inventiva, que acolha a diversidade, mas acima de tudo a novidade, a 
transformação da vida; uma educação problematizadora, que produza coletivamente pensamento, situando-se contra a obviedade do seu tempo; uma educação engajada a ampliar sentidos, sentindo.

Que os termos gênero e educação, possam se desligar da vontade de produzir fôrmas de ação e abrir-se para o acontecimento da vida, pois "a gente só se equilibra em movimento"3 (LOURO, 2004). Afinal, "a vida é como um porto que a gente acaba de chegar é nunca"4. Esse movimento é um desafio também para nós que, como mulheres e professoras, também assumimos posições de sujeitos de gênero em meio a processos de ensino-aprendizagem que ora propomos borrar e transgredir. Em outros termos, reconhecemos os desafios que nossa aposta coloca, inclusive para nós, em nós!

Que em nome da educação em vez de seguirmos transmitindo conhecimentos prontos, generificados, possamos abrir espaços de encontro e problematização, possamos alçar o não passível de ser vivido: uma educação obscena afeita a desfazer gênero, uma educação que acolha a novidade da vida, aberta à experimentação, como uma força embrionária, uma fagulha saltitante, um alvo que não espera a seta, um fogo que irrompe. Afinal, a que educação queremos dar vida, que corpos queremos encenar, que relações de gênero queremos viver e tecer, que sujeitos queremos formar? Que hiper mulheres podemos ser?

\section{REFERÊNCIAS}

BALESTRIN, P. A \& SOARES, R (2012). "Etnografia de tela": uma aposta metodológica. In: MEYER, D. E. \&PARAÍSO, M. A. (org.). Metodologias de Pesquisas Pós-Críticas em Educação, (p. 87-110). Belo Horizonte: Mazza.

BENTO, B. A reinvenção do corpo: sexualidade e gênero na experiência transexual. Rio de Janeiro: Garamond, 2006.

BUTLER, J. Corpos que pesam: sobre os limites discursivos do 'sexo'. In: LOURO, G. L. (org.). O corpo educado: pedagogias da sexualidade (p. 151-172). Belo Horizonte: Autêntica, 2007.

BUTLER, J. Problemas de gênero: feminismo e subversão da identidade. $3^{a}$ ed. Rio de Janeiro: Civilização Brasileira, 2010.

CALDEIRA, M. C. da S., \&PARAÍSO, M. A. Tecnologias de gênero, dispositivo de infantilidade, antecipação da alfabetização: conflitos na produção de corpos generificados. Educação e Pesquisa, v. 42 (3), p. 755-772, 2016.

CARDOSO, L. \& PARAÍSO, M. Tecnologia de gênero e a produção de sujeitos no currículo de aulas experimentais de ciências. Currículo sem fronteiras, v. 15, p. 155-177, 2015.

CARDOSO, L. Relações de gênero, ciência e tecnologia no currículo de filmes de animação. Estudos feministas, Florianópolis, v. 24, n. 2, p. 463-484, 2016.

CARVALHAR, D. L. Currículo da Educação Infantil sexualidades e heteronormatividades na produção de identidades. In: PARAÍSO M. A. (org.). Pesquisas sobre currículos e culturas (p. 31-52). Curitiba: CRV, 2010. 
CORBIN, A. O encontro dos corpos. In: CORBIN, A., COURTINE, J. \&VIGARELLO, G., História do corpo: da Revolução à Grande Guerra. p. 181-266, 2ª ed. Petrópolis, RJ: Vozes, 2008. FOUCAULT, M. Do governo dos vivos: curso no Collège de France, 1979-1980 (excertos). São Paulo (Centro de Cultura Social); Rio de Janeiro: Achiamé, 2010.

FOUCAULT, M. O corpo utópico. In: FOUCAULT, M.O corpo utópico, as heterotopias. São Paulo: n-1 Edições, 2013.

FREITAS, D. A. S. O discurso da educação escolar nas HQs do Chico Bento. Dissertação de mestrado, Universidade Federal de Minas Gerais, Belo Horizonte, MG, Brasil, 2008.

GERACE, R. Cinema explícito. Representações cinematográficas do sexo. São Paulo: Perspectiva, 2015.

KINDEL, E. A. I. A natureza no desenho animado ensinando sobre homem, mulher, raça, etnia e outras coisas mais... Tese de doutorado, Universidade Federal do Rio Grande do Sul, Porto Alegre, RS, Brasil, 2003.

KUIKURO, T., FAUSTO, C., \&SETTE, L. (diretores). As Hiper Mulheres [documentário, drama] [dvd, 80 min.]. Tecnologia digital. Brasil, 2012.

LAVY, V., \&SAND, E. On the origins of gender human capital gaps: short and long term consequence of teachers stereotypical biases. National Bureau of Economic Research, Cambridge, 2015. Recuperado em: 5 dezembro, 2016, em http://www.nber.org/papers/ w20909.pdf, 2015.

LOURO, G. L. Nas redes do conceito de gênero. In: LOPES, M. M.; MEYER, D. E. E., \& WALDOW, V. R. (org.). Gênero e Saúde (p. 7-17). Porto Alegre: Artes Médicas, 1995.

LOURO, G. L. Um corpo estranho: ensaios sobre sexualidade e teoria queer. Belo Horizonte: Autêntica Editora, 2004.

MARTINS, A. F. As hiper mulheres kuikuro: apontamentos sobre cinema, corpo e performance. Revista Sociedade e Estado, v.29 (3), 747-766, 2014.

MEYER, D. E. E., MELLO, D. F. de, VALADÃO, M. M., AYRES, J. R. de C. M. "Você aprende. A gente ensina?’. Interrogando relações entre educação e saúde desde a perspectiva da vulnerabilidade. Caderno de Saúde Pública, v. 22 (6), 1335-1342, 2006.

MEYER, D. E. E. Gênero e educação: teoria e política. In: LOURO, G. L.; FELIPE, J.; GOELLNER, S. V. (org.). Corpo, gênero e sexualidade: um debate contemporâneo na educação (p. 9-27). Petrópolis: Vozes, 2008.

MOSÉ, V. Toda palavra. Rio de Janeiro: Editora Record, 2006.

PARAÍSO, M. A. Contribuições dos Estudos Culturais para a educação. Presença Pedagógica. v. 10 (55), p. 53-61, 2004.

PARAÍSO, M. A. Currículo e mídia educativa brasileira: poder, saber e subjetivação. Chapecó: Argos, 2007.

PARAÍSO, M. A., \& GONÇALVES, E. P. A política curricular dos "reagrupamentos" escolares: práticas generificadas no currículo escolar. Colóquio Internacional de Políticas e Práticas Curriculares, João Pessoa, PB, Brasil, 4, nov., 2009.

PARAÍSO, M. A. Raciocínios generificados no currículo escolar e possibilidades de aprender. In: LEITE C.; PACHECO, J. A.; MOREIRA A. F. B. \& MOURAZ, A. (org.), Políticas, fundamentos e práticas do currículo (p. 147-160). Porto: Porto Editora, 2011.

REIS, C. D. Currículo escolar e Gênero: a constituição generificada de corpos e posições de sujeito. Dissertação de mestrado, Universidade Federal de Minas Gerais, Belo Horizonte, MG, Brasil, 2011. 
SABAT, R. Filmes infantis como máquinas de ensinar. Reunião Anual da Associação Nacional de Pós-Graduação e Pesquisa em Educação, GT Educação e Comunicação, Caxambu, MG, Brasil, 25, set.-out, 2002.

SALES, S. R. Orkut.com.escol@: currículos e ciborguização juvenil. Tese de Doutorado, Universidade Federal de Minas Gerais, Belo Horizonte, 2010.

SILVA, A. M., \&MAIA, C. de J. Construindo a imagem da "verdadeira mulher" nas cenas de Deu a Louca na Branca de Neve. Fórum Ensino, Pesquisa, Extensão e Gestão. Unimontes, Belo Horizonte, MG, Brasil, 8, set., 2014.

SILVA, T. T. Documentos de identidade: uma introdução às teorias do currículo. Belo Horizonte: Autêntica, 2002.

VASCONCELOS, M; BALESTRIN, P.; PAULON, S. Escutar Silêncios, povoar solidões: há vida secreta nas palavras. Fractal, Rev. Psicol., v. 25, n. 3, p. 603-628, 2013.

VASCONCELOS, M. \& SEFFNER, F. A pedagogia das políticas públicas de saúde: normas e fricções de gênero na feitura de corpos. Cadernos Pagu (44), p. 261-297, 2015.

VASCONCELOS, M. \& ZAGO, L. Mercados da/de carnes: corpos imprevistos na biopolítica. Fractal: Revista de Psicologia, v. 27, n. 3, p. 219-227, 2015.

VEYNE, P. (2008). Como se escreve a história: Foucault revoluciona a história. Brasília: Universidade de Brasília.

\section{NOTAS}

${ }^{1}$ Entendemos que aquilo que denominamos de natural é também uma construção social. Todavia, nesta passagem específica, estamos nos referindo a algo que efetivamente poderia ser considerado como da natureza humana (se assim podemos dizer), uma vez que, ao menos até o presente momento, esta é a única certeza que temos referente à vida: não sabemos quando partiremos, ou como se dará esse processo, mas sabemos que a morte chegará para todas/os e cada um/a de nós.

${ }^{2}$ Nesse cenário, os homens também têm sua masculinidade engessada em um padrão muitas vezes impossível de ser atingido, além de serem, homens e mulheres ensinados/as a naturalizar práticas e comportamentos machistas, nocivos a ambos.

${ }^{3}$ Guacira Louro, faz referência à fala do palhaço no filme brasileira de Cacá Diegues "Bye bye Brasil".

${ }^{4}$ A mesma autora (2004) utilizada fala de outro personagem, o Taoca, de um outro filme brasileiro de estrada chamado "Deus é brasileiro".

Submetido: 27/03/2017

Aprovado: 16/07/2017

Contato:

Universidade Federal de Sergipe Departamento de Educação

Campus Prof. Alberto Carvalho Av. Vereador Olímpio Grande, s/n 